\title{
Density, size structure and reproductive characteristics of fissiparous brittle stars in algae and sponges: evidence for interpopulational variation in levels of sexual and asexual reproduction*
}

\author{
Philip V. Mladenov ${ }^{1}$, Roland H. Emson ${ }^{2}$ \\ ${ }^{1}$ Biology Department, Mount Allison University, Sackville, New Brunswick, Canada E0A 3C0 \\ ${ }^{2}$ Department of Zoology, King's College (KQC), Kensington Campus, Campden Hill Road, London W8 7AH, United Kingdom
}

\begin{abstract}
This study documents density, size structure and levels of sexual and asexual reproduction in populations of fissiparous brittle stars occupying algal turf and sponge habitats in Jamaica, Belize and Bermuda. Ophiocomella ophiactoides allowed comparison between algal turf habitats in Jamaica and Belize; Ophiactis savignyi allowed comparisons between algal turf and sponge habitats at each location. In algal turf growing in protected Jamaican coves, $O$. ophiactoides was present at moderate to high densities (max. $26 \mathrm{dl}^{-1}$ of algae). Asexual reproduction predominated among the numerous small individuals, whereas sexual reproduction was confined to a few large individuals. In contrast, in algal turf growing in more exposed backreef and reef crest areas at Belize, this species was present at very low densities ( $\max .1 \mathrm{dl}^{-1}$ ), showed a higher incidence of fission at all body sizes, and was exclusively asexual. Both mean body size and density of $O$. savignyi were greater in sponges than in algal turf at each location. Sponge-dwelling populations contained asexual individuals as well as a comparatively small number of large sexually reproducing individuals, whereas epiphytic individuals were almost all asexual. These differences are considered in relation to habitat stability and other ecological factors. Algal clumps and sponges frequently contained all-male or all-female clusters of fissiparous brittle stars, suggesting clonal aggregations. Male $O$. savignyi predominated in sponges: no sexual females were discovered in samples taken from Harrington Sound, Bermuda, and females constituted only 11 and $17 \%$, respectively, of sexual individuals examined from sponges in Jamaica and Belize.
\end{abstract}

\section{INTRODUCTION}

Fissiparous brittle stars possess the ability to produce solitary, mobile modules by binary fission. Although a systematically diverse assemblage of species, they share a number of remarkably similar traits including a tropical and sub-tropical distribution, an often epiphytic or epizoic habit, small adult size $(<7 \mathrm{~mm}$ disc diameter), and mainly hexamerous symmetry (Emson \& Wilkie 1980, Mladenov et al. 1983, Emson et al. 1985). The adaptive significance of this shared suite of traits is presently unclear (Mladenov \& Emson 1984).

Most, perhaps all, fissiparous species of brittle star

\footnotetext{
- Contribution No. 1159 of the Bermuda Biological Station for Research; contribution No. 408 of the Discovery Bay Marine Laboratory, University of the West Indies, Jamaica
}

are heterogonic. Fission predominates, and is the chief means of recruitment, in populations of several species at a site in Discovery Bay, Jamaica (Mladenov et al. 1983, Emson et al. 1985). Individuals in these populations possess only limited capacity for sexual reproduction through broadcast spawning (Mladenov \& Emson 1984). Mladenov \& Emson (1984) briefly considered the role of intermittent sexuality in these fissiparous brittle stars and suggested that sex serves to maintain limited larval dispersal allowing escape from deteriorating habitats and the potential to colonize new, distant habitats. They also suggested that new populations could be founded by settlement of a single larva and may thus consist of clonal aggregations.

The populations at the Discovery Bay, Jamaica, site may not be characteristic of all populations. Fissiparous brittle stars are distributed throughout the West Indies 
(Parslow \& Clark 1963) in a variety of habitats and it is possible that they show interpopulational variation in mode of reproduction, allocating more energy to sexual reproduction under certain circumstances and more to asexual reproduction under others. Such variation has already been documented for a few species of marine invertebrates including some sea stars (James \& Pearse 1969. Crump \& Barker 1985) and sea anemones (Chia 1976, Bell 1982 p. 179-182, Hoffmann 1986).

In this study we document population densities, population size structure, and reproductive characteristics of fissiparous brittle stars in algal turf and sponge habitats at 3 locations in the tropical and sub-tropical western Atlantic. We demonstrate striking within- and between-habitat differences in populational and reproductive characteristics for several species and examine the ecological correlates of these differences.

\section{MATERIALS AND METHODS}

We visited 3 locations during summer 1984: Jamaica (29 Jun to 26 Jul), the central barrier reef complex of Belize (28 Jul to 9 Aug), and Bermuda (12 Aug to 4 Sep). We visited Jamaica a second time in winter (26 Jan to 1 Feb 1985). An initial objective of our study was to assess the range of habitats occupied by fissiparous brittle stars. At Jamaica, we searched intensively for fissiparous brittle stars by snorkeling and SCUBA diving at many sites in Discovery Bay and in the mangrove swamp near Falmouth (Fig. 1). The sites in Discovery Bay included shallow $(<2 \mathrm{~m})$ backreef habitats and deeper (to $30 \mathrm{~m}$ ) forereef habitats, shallow $(<2 \mathrm{~m}$ ) rocky coves, shallow $(<2 \mathrm{~m})$ rock rubble habitats and shallow $(<3 \mathrm{~m})$ seagrass beds. We were unable to search intensively for fissiparous brittle stars in the interstitial spaces of living coral on the forereef. We also surveyed sites near Montego Bay, Lances Bay, Kingston Harbour and Port Antonio (Fig. 1). These sites encompassed a variety of environments including shallow $(<3 \mathrm{~m}$ ) backreef habitats, rocky coves, rock rubble substrata and mangroves. We also searched for fissiparous brittle stars at various sites on the central barrier reef complex of Belize (Fig. 2). Samples were collected from forereef (to depths of $15 \mathrm{~m}$ ) (not from living coral heads), shallow $(<2 \mathrm{~m}$ ) backreef (including seagrass beds), and reef crest areas east and south of South Water Cay and east of Carrie Bow Cay. We also collected $(<3 \mathrm{~m})$ from the extensive mangrove communities of Twin Cays and Tobacco Range (Fig. 2). Finally, we searched for fissiparous brittle stars at many sites around Bermuda (Fig. 3). These sites encompas-

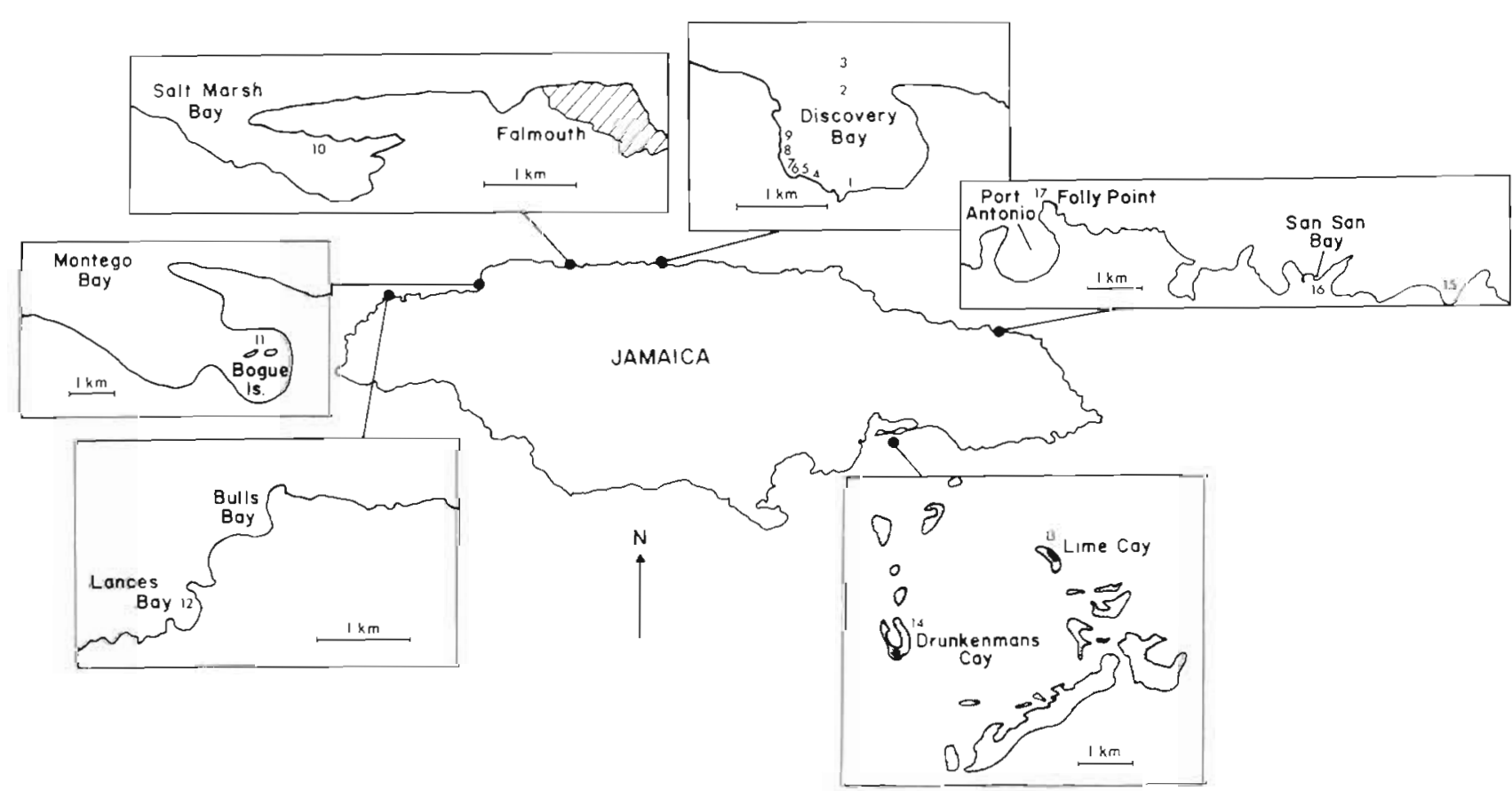

Fig. 1. Jamaica, showing sites searched for fissiparous brittle stars. 1: Columbus Park Reef (from depths of 2 to $20 \mathrm{~m}$ ), $2:$ One Palm Island $(<3 \mathrm{~m})$, 3: Forereef $(1.5$ to $30 \mathrm{~m})$, 4: Clone Cove $(<1 \mathrm{~m})$, 5: Station Ramp $(<2 \mathrm{~m})$, 6: Maze Cove $(=$ Blue Maze) $(<2 \mathrm{~m})$, 7 : Bath Cove $(<2 \mathrm{~m})$, 8: Sally Cove $(<2 \mathrm{~m})$, 9: Wahle Cove $(<1 \mathrm{~m}) ; 10$ : Falmouth mangrove $(<3 \mathrm{~m}) ; 11$ Bogue Is. mangrove $<2 \mathrm{~m})$; 12: Lances Bay $(<1 \mathrm{~m})$; 13: Lime Cay $(<4 \mathrm{~m}), 14$ : Drunkenman's Cay $(<4 \mathrm{~m}) ; 15$ : Dragon Bay $(<3 \mathrm{~m}), 16$ : San San Bay $(<3 \mathrm{~m}), 17$ : Folly Point $(<1 \mathrm{~m})$ 
sed several different benthic environments including the rocky littoral, rocky subtidal (to $5 \mathrm{~m}$ ), shallow $(<3 \mathrm{~m})$ rock rubble substrata, mangroves $(<3 \mathrm{~m})$ and coral reefs (to depths of $20 \mathrm{~m}$ ).

Procedures used for collecting and processing fissiparous brittle stars are detailed in Mladenov et al. (1983). All fissiparous brittle stars found were identified and enumerated and the habitat from which they were obtained noted. The disc diameter of each specimen at the widest part of the disc was used as an estimate of body size. Size-frequency distributions were constructed and compared by means of parametric tests using log-transformed data (the size-frequency distributions were almost always strongly skewed to the right). Each specimen was assigned to a regeneration category as follows: 1 = length of regenerating arms $<25 \%$ length of long arms; 2 = length of regenerating arms 25 to $50 \%$ length of long arms; $3=$ length of regenerating arms 51 to $75 \%$ length of long arms; $4=$ length of regenerating arms $>75 \%$ length of long arms. The aboral covering was then removed from each specimen to determine if gonads were present. If so, the sex of the specimen was recorded.

When fissiparous brittle stars were found in algal clumps, the alga was identified and the volume of the clump determined by displacement in seawater. The density of each species of fissiparous brittle star in the clump was then expressed as number per decilitre $\left(\mathrm{dl}^{-1}\right)$ of alga.

Sponges occupied by fissiparous brittle stars were located by making a slit in the wall of many different sponges with a dive knife and examining the interior, sometimes with the aid of an underwater magnifying device (Mladenov \& Powell 1986). Occupied sponges were removed whole, placed separately in plastic bags and returned to the laboratory. Each sponge was dissected and all brittle stars were removed. The entire sponge was generally examined although, in some instances, it was practical to examine only a portion of the sponge because of the very large numbers of brittle stars present. The volume of each sponge was measured by displacement and the density of brittle stars expressed as number $\mathrm{dl}^{-1}$ of sponge.

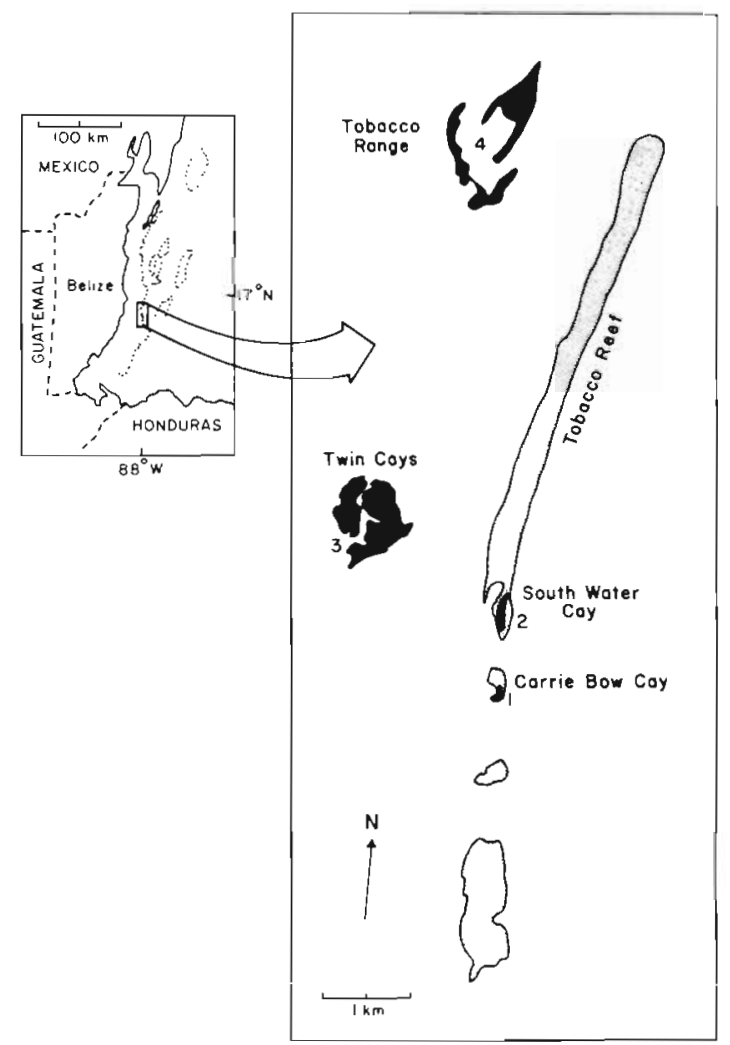

Fig. 2. Belize, showing parts of barrier reef complex and sites searched for fissiparous brittle stars. 1: Carrie Bow Cay (depths $<15 \mathrm{~m}$ ), 2: South Water Cay $(<3 \mathrm{~m})$, 3: Twin Cays mangrove $(<3 \mathrm{~m}), 4$ : Tobacco Range mangrove $(<3 \mathrm{~m})$. Black areas: cays; shaded areas: barrier reef
Fig. 3. Bermuda, showing sites searched for fissiparous brittle stars. 1: Fort St. Catherine (depths $<4 \mathrm{~m}), 2$ : Achilles Bay $(<4 \mathrm{~m}), 3$ : Coot Pond $(<1 \mathrm{~m}), 4$ : Tobacco Bay $(<4 \mathrm{~m}), 5$ : reef seaward of Nonsuch Is. $(15$ to $30 \mathrm{~m}), 6$ : Castle Is. $(<4 \mathrm{~m}), 7$ : Tucker's Town Bay $(<4 \mathrm{~m})$, 8: Castle Harbour patch reefs ( 3 to $20 \mathrm{~m}$ ), 9: Walsingham Bay $(<3 \mathrm{~m})$, 10: Walsingham Pond $(<8 \mathrm{~m}), 11$ : Coney Is. $(<3 \mathrm{~m}), 12$ : Bailey's Bay $(<4 \mathrm{~m}), 13$ : Church Bay $(<3$ m), 14: Shark Hole $(<3 \mathrm{~m}), 15$ : The Devil's Hole $(<3 \mathrm{~m}), 16$ : Flatts Bridge $(<3$ $\mathrm{m}), 17$ : Green Bay $(<3 \mathrm{~m}), 18$ : Trunk is. $(<3 \mathrm{~m})$, 19: Patton Point $(<4 \mathrm{~m}), 20$ : Gravelly Bay $(<3 \mathrm{~m}), 21$ : Hungry Bay $(<3 \mathrm{~m}), 22$ : 'Fairyland' Bay $(<4 \mathrm{~m}), 23$ : Lagoon Patch Reefs ( 3 to $20 \mathrm{~m}$ ), 24 : North Rock ( 3 to $20 \mathrm{~m}$ )

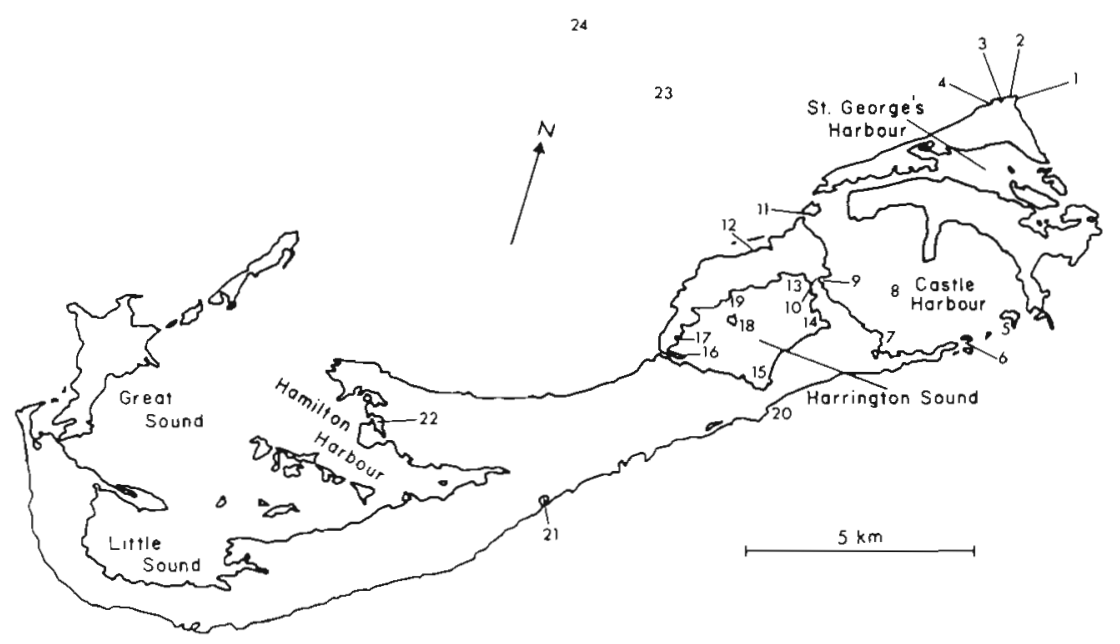




\section{RESULTS}

\section{Occurrence}

During this study, 5 species of fissiparous brittle stars from 3 families were found (Table 1). Three species, Ophiostigma isocanthum, Ophiactis savignyi and Ophiocomella ophiactoides, were present at Jamaica, Belize and Bermuda; one species, Ophiactis algicola, was found only at Jamaica and Bermuda; another species, Ophiactis lymani, was encountered only at Bermuda and represents the first record of this species at this location.

\section{Distribution and relative abundance}

Jamaica. Fissiparous brittle stars were present at many sites around Jamaica (Table 2). Ophiactis savignyi was abundant and widespread in coralline red and calcareous green algae covering rocky substrata in shallow coves along the shore. It was also found in very large numbers within the excurrent canals of some sponges occupying mangrove prop roots (Table 2, Site 10). Ophiocomella ophiactoides was abundant and widespread in coralline red and calcareous green algae in shallow coves and, to a lesser extent, in backreef habitats (Table 2). Ophiostigma isocanthum and Ophiactis algicola were rarely found at Jamaica. The former was sometimes present in coralline red and calcareous green algae in coves and backreef areas as well as at the base of blades of the seagrass Thalassia testudinum at one site (Table 2, Site 5). The latter was occasionally encountered in coralline red algae at one site (Table 2, Site 6).

Central Barrier Reef, Belize. Ophiactis savignyi and Ophiocomella ophiactoides were present in low to moderate numbers in calcareous green algae in the backreef and reef crest areas of Carrie Bow Cay and Southwater Cay (Table 2, Sites 1 and 2). Ophiostigma isocanthum occurred rarely at these sites (Table 2). Ophiactis savignyi was also found in extremely high numbers in the excurrent canals of some mangrove sponges at Twin Cays (Table 2, Site 3).

Bermuda. Fissiparous brittle stars at Bermuda were abundant only in Harrington Sound (Table 2, Sites 13 to 19), an almost totally enclosed salt-water lake (Morris et al. 1977). Here, Ophiactis savignyi was common in coralline red algae and sponges on rocky substrate in shallow $(<3 \mathrm{~m})$ water. Ophiactis algicola and Ophiactis lymani were abundant in coralline red algae and were encountered occasionally in sponges (Site 16). Ophiostigma isocanthum was rarely found (except at Site 17) and limited to coralline red algae. Only 8 specimens of Ophiocomella ophiactoides were found despite intensive search. They were present under rocks in shallow $(<2 \mathrm{~m})$ water at several sites along the outer coast and in deeper $(10$ to $20 \mathrm{~m})$ water within limestone nodules on a reef seaward of Nonsuch Island (Site 5).

In summary, our surveys indicated that algal turf in shallow water and sponges in mangroves and, in the case of Bermuda, a salt-water lake, were favourable habitats for fissiparous brittle stars.

\section{Density in algal habitats}

In this and the following sections we examine the population structure and reproductive characteristics of the 2 common species (Ophiocomella ophiactoides and Ophiactis savignyi) that allow within-habitat (i.e. within the same habitat at different locations) and

Table 1. Occurrence of fissiparous brittle stars at the 3 locations. $x$ : Present; -: absent

\begin{tabular}{|c|c|c|c|}
\hline Species & Jamaica & $\begin{array}{c}\text { Barrier Reef } \\
\text { Belize }\end{array}$ & Bermuda \\
\hline \multicolumn{4}{|l|}{ Amphiuridae } \\
\hline Ophiostigma isocanthum (Say) ${ }^{1}$ & $x$ & $x$ & $x$ \\
\hline \multicolumn{4}{|l|}{ Ophiactidae } \\
\hline Ophiactis algicola (H. L. Clark) & $x$ & -2 & $x$ \\
\hline Ophiactis lymani (Ljungman) & - & - & $x$ \\
\hline Ophiactis savignyi (Muller \& Troschel) & $x$ & $x$ & $x$ \\
\hline \multicolumn{4}{|l|}{ Ophiocomidae } \\
\hline Ophiocomella ophiactoides (H. L. Clark) & $x$ & $x$ & $x$ \\
\hline \multicolumn{4}{|c|}{$\begin{array}{l}{ }^{1} \text { Both 6-armed (fissiparous) and 5-armed (putatively non-fissiparous) forms have been reported (Koehler } 1913, \text { Clark } 1933, \\
\text { 1942, Thomas 1962). Hotchkiss (1982) suggests that the fissiparous forms may be specifically distinct and refers to such } \\
\text { specimens from Carrie Bow Cay, Belize, as Ophiostigma sp. The 6-armed form was by far the most numerous in all of our } \\
\text { samples } \\
{ }^{2} \text { Hendler \& Littman (1986) report finding small numbers of } O \text {. algicola at this location }\end{array}$} \\
\hline
\end{tabular}




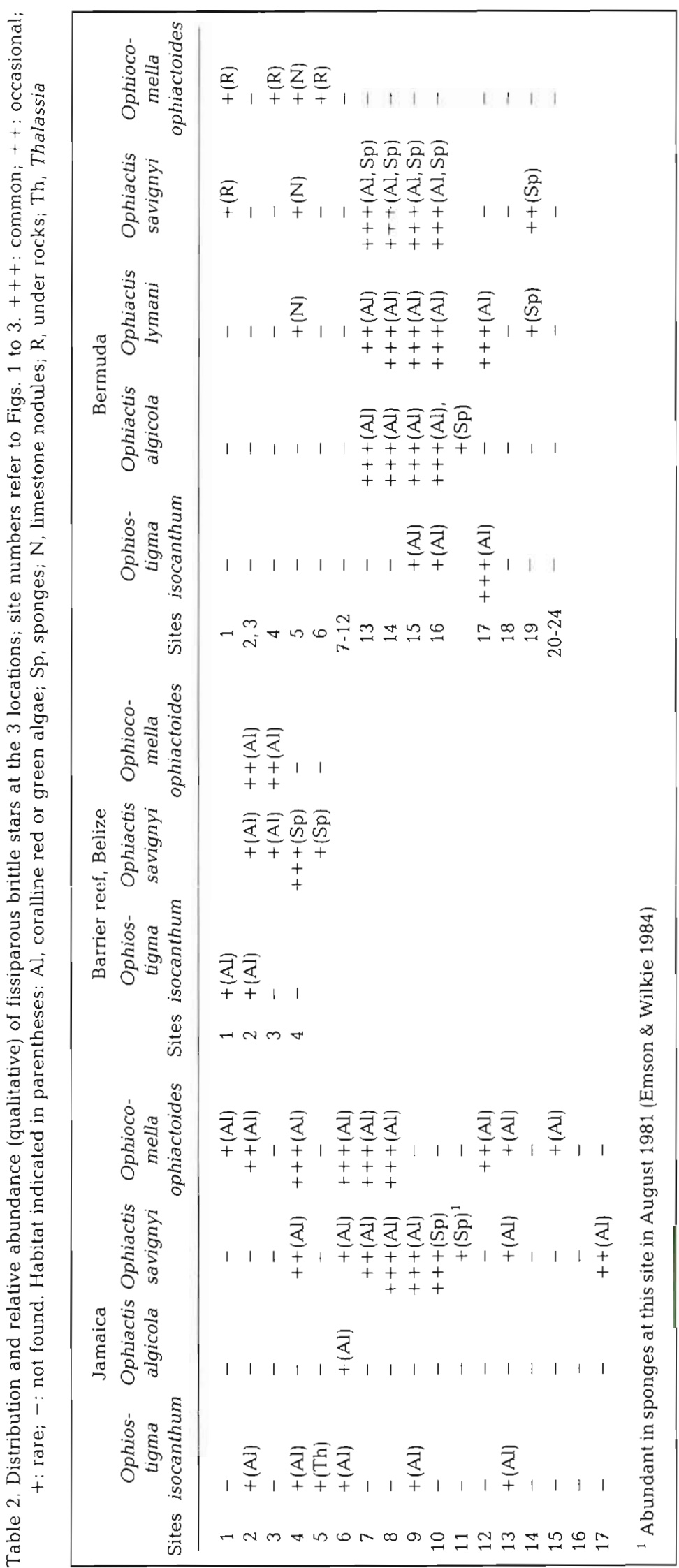


between-habitat (i.e. algae vs sponges) comparisons of population structure and levels of sexual and asexual reproduction.

Discovery Bay, Jamaica. Ophiocomella ophiactoides occurred mainly in coralline red algae (principally Amphiroa rigida and Amphiroa fragilissima) and in the calcareous green alga Halimeda opuntia (Table 3). Mean densities in these microhabitats ranged from moderate to high (maximum of about $26 \mathrm{dl}^{-1}$ of algae) (Table 3). At Site 6 this species was also found in the red alga Gracilaria(?) sp. at moderate density (Table 3). Results of a $\chi^{2}$ test (variance to mean ratio) for agreement with a Poisson series (Elliott 1977) indicate that $O$. ophiactoides was almost always contagiously distributed in these 3 algal microhabitats (Table 3). Ophiactis savignyi was present in Amphiroa spp. and $H$. opuntia at generally much lower densities (maximum of about $7 \mathrm{dl}^{-1}$ of algae) than $O$. ophiactoides (Table 3).

Carrie Bow Cay, Belize. Ophiocomella ophiactoides was present at low densities in Halimeda opuntia and was very rare (density could not be determined) in Amphiroa fragilissima (Table 3). Ophiactis savignyi was present in very low densities in $H$. opuntia and was very rare (density could not be determined) in $A$. fragilissima. There was no evidence of contagious distribution in these species at this site.

Harrington Sound, Bermuda. Ophiocomella ophiac- toides was not found at this location. Ophiactis savignyi was found at moderately high densities in Amphiroa spp. and was always contagiously distributed (Table 3).

\section{Size structure and reproductive characteristics in algal habitats}

Information on size-frequency, state of regeneration and sexual status of epiphytic populations of common fissiparous brittle stars at different locations is presented in Fig. 4.

Ophiocomella ophiactoides. The Jamaican population of $O$. ophiactoides was strongly dominated by small individuals. Weighted mean value of regeneration category increased steadily with size. The small individuals in the population thus almost always showed evidence of recent fission whereas the few large individuals were generally symmetrical in shape. (It is unlikely that small individuals were the result of the splitting of large individuals, as this implies that considerable decrease in the disc diameter occurs during regeneration; observations of regenerating specimens in the laboratory [Mladenov et al. 1983] show that the original disc diameter is maintained.) Fission was thus occurring mainly in small individuals. It was only the larger individuals that contained recognizable gonads, and both males and females were present (sex

Table 3. Density ( $\overline{\mathrm{x}} \pm \mathrm{SD}$ individuals $\mathrm{dl}^{-1}$ ) and $\mathrm{s}^{2} / \overline{\mathrm{x}}$ ratio (in parentheses) of common fissiparous brittle stars in algae at sites in Discovery Bay, Jamaica, Carrie Bow Cay, Belize, and Harrington Sound, Bermuda. Results of $\chi^{2}$ test (variance to mean ratio) for agreement with a Poisson series are indicated: $\cdot p<0.05 ; \cdots p<0.01 ; \cdots p<0.001$; ns: not significant

\begin{tabular}{|c|c|c|c|c|}
\hline Site & Algae & $\begin{array}{l}\text { No. of } \\
\text { samples }\end{array}$ & $\begin{array}{c}\text { Ophiactis } \\
\text { savignyi }\end{array}$ & $\begin{array}{l}\text { Ophiocomella } \\
\text { ophiactoides }\end{array}$ \\
\hline \multicolumn{5}{|c|}{ Jamaica } \\
\hline \multirow[t]{2}{*}{4} & Amphiroa spp. & 6 & $0.5 \pm 0.9(1.6)^{\mathrm{ns}}$ & $4.0 \pm 8.0(16.0)^{\cdots}$ \\
\hline & Halimeda opuntia & 3 & $3.9 \pm 3.4(3.0)^{\circ}$ & $26.3 \pm 20.5(16.0)^{\cdots} \cdot$ \\
\hline \multirow[t]{3}{*}{6} & Halimeda opuntia & 10 & $0.2 \pm 0.5(1.2)^{\mathrm{ns}}$ & $11.3 \pm 11.5(11.7) \cdots$ \\
\hline & Amphiroa spp. & 2 & - & $1.6 \pm 5.4(1.8) \cdots$ \\
\hline & Gracilaria (?) sp. & 4 & - & $10.6 \pm 6.8(4.4) \cdots$ \\
\hline 7 & Amphiroa spp. & 9 & $0.9 \pm 2.0(4.4)^{\cdots}$ & $3.4 \pm 3.9$ \\
\hline \multirow[t]{2}{*}{8} & Amphiroa spp. & 6 & $7.1 \pm 6.1(5.2) \cdots$ & - \\
\hline & Halimeda opuntia & 2 & $1.6 \pm 2.2(3.0)^{\mathrm{ns}}$ & $2.1 \pm 0.6(0.2)^{\mathrm{ns}}$ \\
\hline 9 & Amphiroa spp. & 4 & $2.5 \pm 2.2(1.9)^{n s}$ & - \\
\hline \multicolumn{5}{|c|}{ Belize } \\
\hline \multirow[t]{2}{*}{1} & Halimeda opuntia & 8 & $0.3 \pm 0.5(0.8)^{\mathrm{ns}}$ & $1.2 \pm 1.1(1.0)^{\mathrm{ns}}$ \\
\hline & Amphiroa fragilissima & 7 & Very rare & Very rare \\
\hline \multicolumn{5}{|c|}{ Bermuda } \\
\hline 13 & Amphiroa spp. & 4 & $5.1 \pm 4.9(4.7)^{\cdots}$ & - \\
\hline 14 & Amphiroa spp. & 4 & $14.1 \pm 11.2(8.9)^{\cdots} \cdot$ & - \\
\hline 15 & Amphiroa spp. & 3 & $17.2 \pm 21.6(27.1) \cdots$ & - \\
\hline 16 & Amphiroa spp. & 3 & $7.6 \pm 5.7(4.3)^{\circ}$ & - \\
\hline 17 & Amphiroa spp. & 1 & - & - \\
\hline
\end{tabular}


Fig. 4. Ophiocomella ophiactoides and Ophiactis savignyi. Size-frequency distribution (histograms), regeneration category as a function of body size (dots). and sexual status (shaded and black areas of histogram) for epiphytic populations. Sample location, sample size, mean body size ( $\pm 1 S D)$ and number of males and females are provided for each sample. The best model equation has been fitted to each set of data points for weighted mean value of regeneration category using the CURFIT program of Spain (1982)

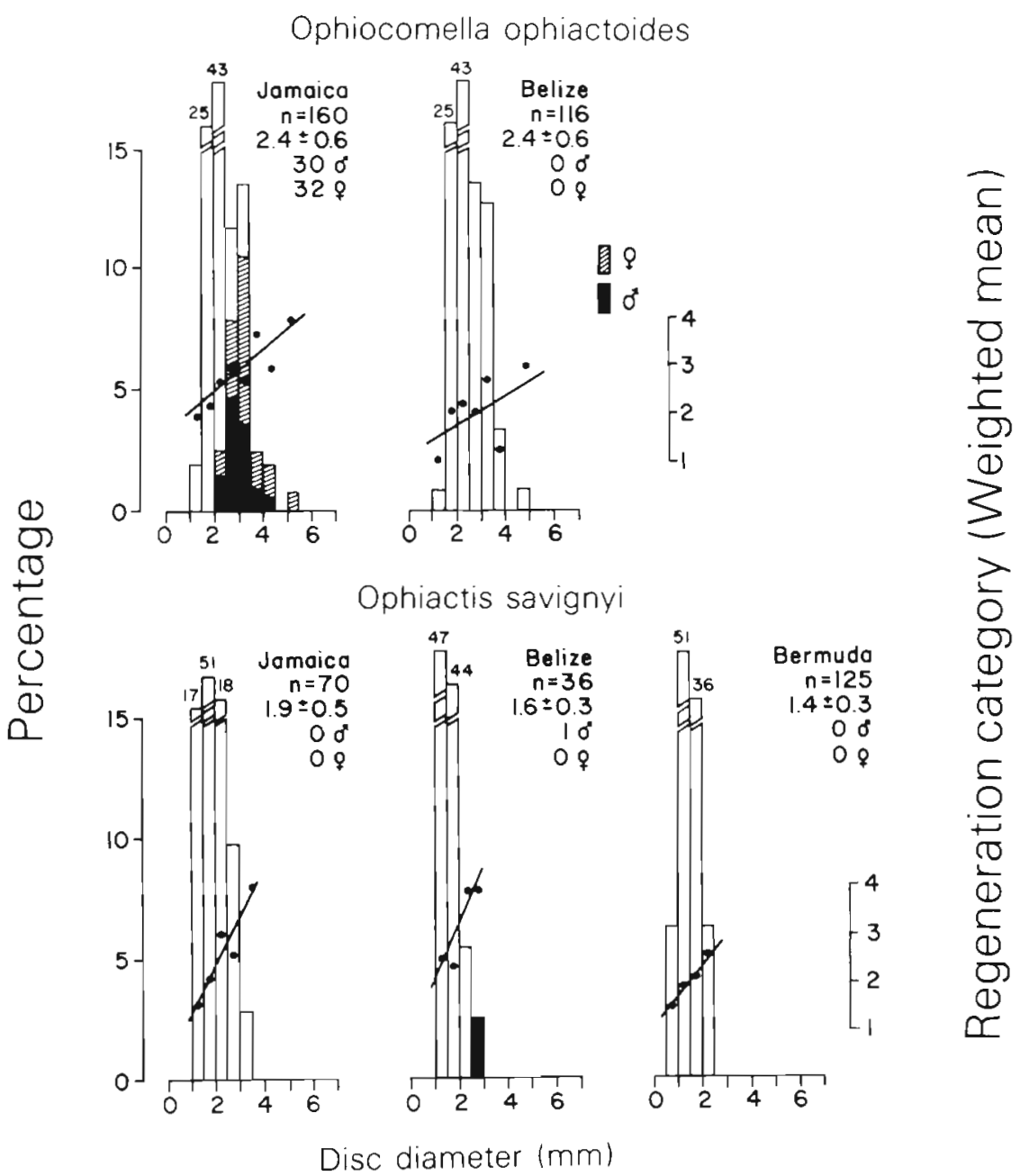

ratio not different from unity, $\left.\chi^{2}, p>0.05\right)$; large individuals were thus reproducing mainly sexually.

The Belizean population of Ophiocomella ophiactoides was also dominated by small individuals and the mean body size of this population was the same as for the Jamaican population ( $t=0.16, p>0.05)$. The Belizean population also showed the same general increase in regeneration category with size, although the distribution of values was lower overall (Kolmogorov-Smirnov 2 -sample test, $p<0.05$ ). In other words, individuals in all size categories showed a higher incidence of recent fission compared to the Jamaican population. Furthermore, of the 116 specimens examined, none possessed recognizable gonads. The Belizean population thus appears to have had higher levels of fission than the Jamaican population and to have been exclusively asexual at the time of sampling.

Ophiactis savignyi. Epiphytic populations of $O$. savignyi at Jamaica, Belize and Bermuda were dominated by small individuals. The mean body size of the Jamaican population was larger than that of either the
Belizean or Bermudan populations (ANOVA, $F=$ 32.98, p <0.001, followed by Student Newman Keuls test, $p<0.05$ ). However, weighted mean values for regeneration category increased with size at all 3 locations and there was no difference in the distribution of these values between the populations (pair-wise applcation of Kolmogorov-Smirnov 2-sample test, $\mathrm{p}>0.05$ ) suggesting that the frequency of asexual reproduction was about the same at these sites. No individuals from Jamaica or Bermuda contained recognizable gonads and only a single sexual individual (male) was sampled at Belize. These populations thus relied exclusively or almost exclusively on asexual reproduction at the time of sampling.

\section{Characteristics of Ophiocomella ophiactoides in discrete algal clumps at Jamaica}

In winter 1985 we sampled Ophiocomella ophiactoides from 7 discrete clumps of algae obtained from Maze Cove, Jamaica (Fig. 1, Site 4). The characteristics 
of the $O$. ophiactoides in each clump are summarized in Fig. 5. In many clumps there was a tendency for regeneration category to increase with size although in 2 clumps there was a decrease. Sexual individuals were among the largest in each clump. Of the 7 clumps examined, 2 contained only females, 2 were dominated by females, 2 contained only males, and 1 contained males and females in about equal numbers (Fig. 5). There was thus great variability in sex ratio among clumps, suggesting the presence of clonal aggregations within clumps (see 'Discussion'). Overall, 33 females were found and only 12 males (ratio significantly different from 1, $\chi^{2}, \mathrm{p}<0.05$ ).
Size structure, population density and reproductive characteristics of Ophiactis savignyi in sponges

Falmouth mangrove swamp, Jamaica. At this site (Fig. 1, Site 10) we examined ca 30 sponges of various species (Tedania ignis, Spongia spp., Haliclona molitba, Lissodendoryx isodictyalis, Hircinia sp.) on 26 Jul 1984 and found 4 that were colonized by Ophiactis savignyi. On 30 Jan 1985 we revisited the mangrove and examined 42 sponges, finding 5 that were colonized by $O$. savignyi (the brittle stars in only 2 of these 5 sponges were processed). In both instances, all the colonized sponges occurred in close proximity to one

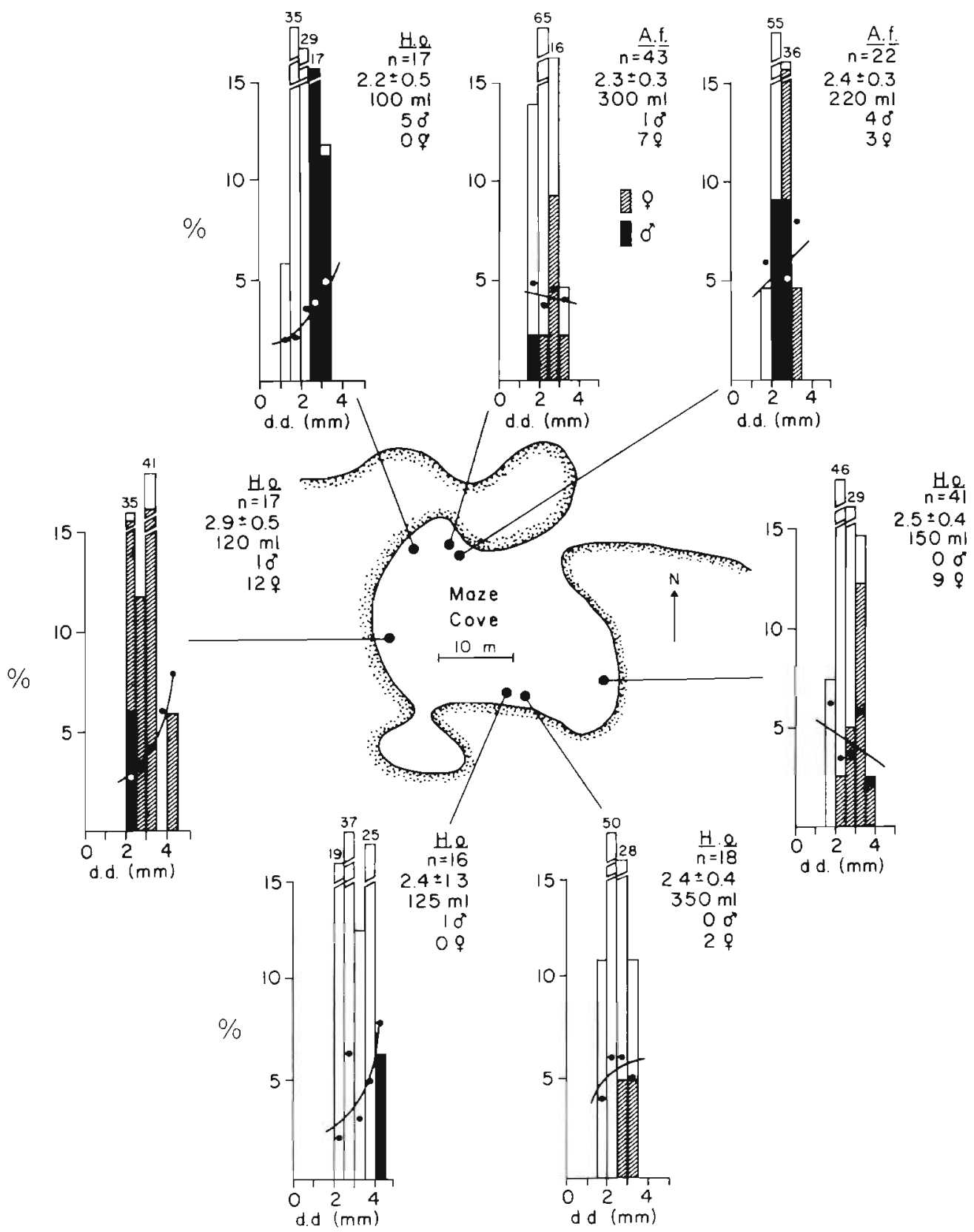

Fig. 5. Ophiocomella ophiactoides. Size-frequency distribution (histograms), regeneration category as a function of body size (dots), and sexual status (shaded and black areas of histograms) for clusters sampled from discrete clumps of algae from Maze Cove (Fig. 1, Site 6), Jamaica. Algal species (H.o.: Halimeda opuntia; A.f. Amphiroa fragilissima), sample size, mean body size $( \pm 1$ SD), and number of males and females are provided for each sample. The best model equation has been fitted to each set of data points for weighted mean value of regeneration category using the CURFIT program of Spain (1982). d.d.: disc diameter 
another on the prop roots of a series of adjacent mangrove trees. The brittle stars were packed tightly into the excurrent cavities of the sponge.

The characteristics of Ophiactis savignyi in each of the 6 sponges that were processed are shown in Fig. 6. Three different sponge species (Haliclona molitba, Tedania ignis, and Lissodendoryx isodictyalis) were colonized. The density of individuals within each sponge was very high, in one instance exceeding 150 $\mathrm{dl}^{-1}$ of sponge. In reality, these density values underrate the very crowded condition of the brittle stars in the sponges as only a small fraction of the volume of each sponge actually consists of cavities large enough for occupation by brittle stars.

The population in each sponge was strongly dominated by a large number of small individuals (Fig. 6). For the 4 sponges for which data on regeneration category are available, values increased rapidly with size indicating that only the small individuals were dividing frequently. Only the largest individuals present in the sponge were sexual. Interestingly, sexual individuals in any one sponge were always of the same sex: 5 of the 6 sponges analyzed contained only males while the remaining sponge contained only females. This suggests the presence of clonal aggregations within sponges (see 'Discussion'). The mean size of individuals in the sponge that contained only females was significantly larger than in the other 5 sponges examined (ANOVA, $F=71.56, p<0.0005$, followed by Student Newman Keuls test, $p<0.05$ ). Of the 1245 individuals examined from all 6 sponges, 110 possessed testes and only 13 possessed ovaries. Therefore, about $10 \%$ of the individuals were sexual and, of these, about $89 \%$ were males.

Twin Cays, Belize. On 3 and 5 Aug we searched for colonized sponges in Twin Cays (Fig. 2, Site 3). About 170 sponges of various species mentioned above were examined and 16 were found to be colonized by Ophiactis savignyi. All 16 of these colonized sponges were found along a roughly $80 \mathrm{~m}$ stretch of mangrove bank. Thus, as in the Falmouth mangrove swamp of Jamaica, a relatively small number of sponges, all in close proximity to
Fig. 6. Ophiactis savignyi. Size-frequency distribution (histograms), regeneration category as a function of body size (dots), and sexual status (shaded and black areas of histograms) for populations present within 6 different sponges sampled from Falmouth mangrove swamp (Fig. 1, Site 10), Jamaica. The sponge species (H.m.: Haliclona molitba; L.i.: Lissodendoryx isodictyalis; T.i.: Tedania ignis), sample size, mean body size $( \pm 1 \mathrm{SD})$, population density ( $\mathrm{dl}^{-1}$ of sponge), and number of males and females are provided for each sample. The best model equation has been fitted to each set of data points for weighted mean value of regeneration category using the CURFIT program of Spain (1982)

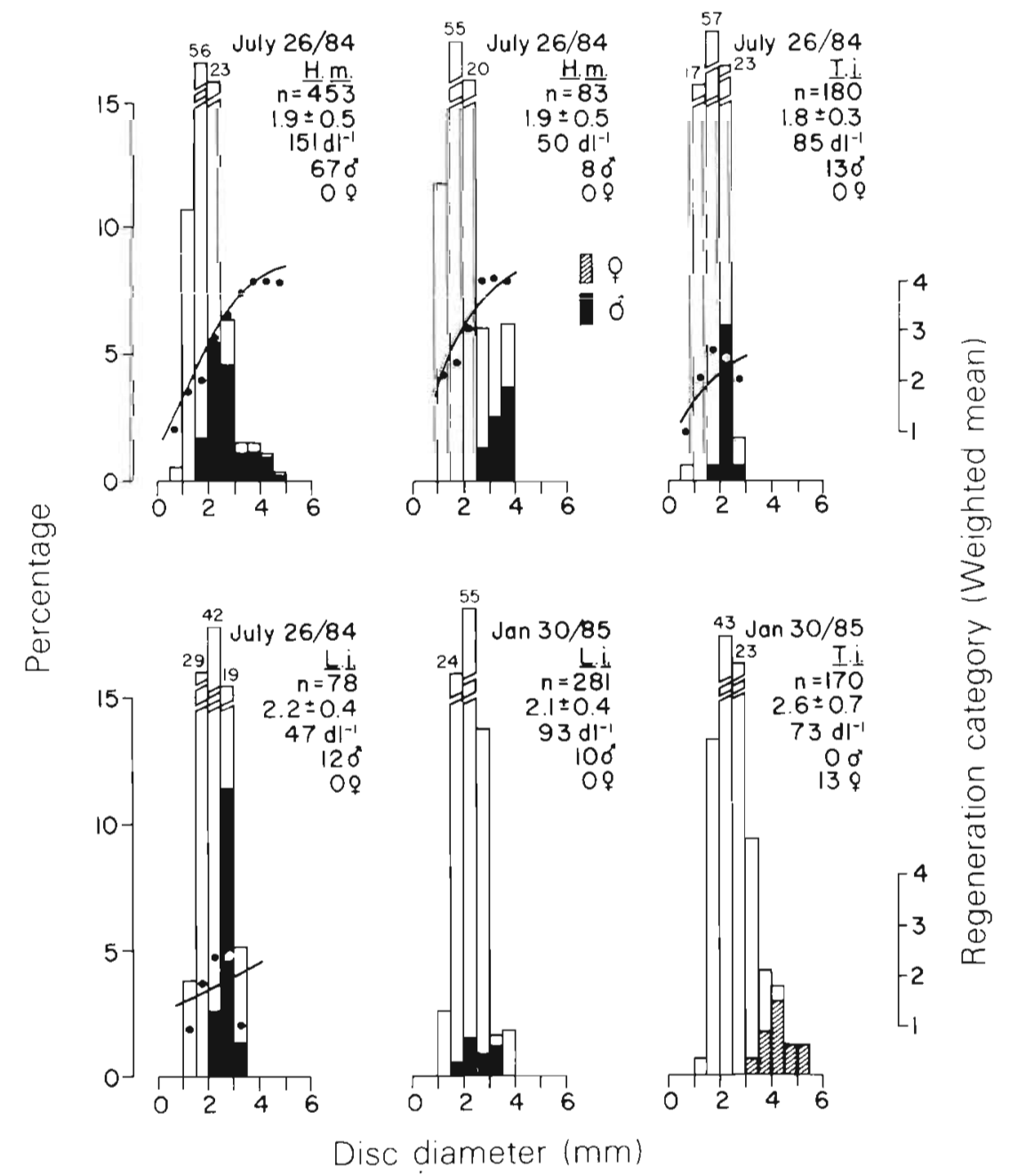


one another, were found colonized by $O$. savignyi. Four different species of sponge were colonized: Haliclona molitba, Tedania ignis, Lissodendoryx isodictyalis and Spongia sp. The first 3 species were also among those colonized in the Falmouth mangrove swamp of Jamaica.

The characteristics of Ophiactis savignyi in each of the 9 sponges processed are presented in Fig. 7. The density of individuals within each sponge was very high, in one instance exceeding $280 \mathrm{dl}^{-1}$. Each sponge contained many small individuals and only a few large individuals. There was a consistently rapid increase in value of regeneration category with increasing body
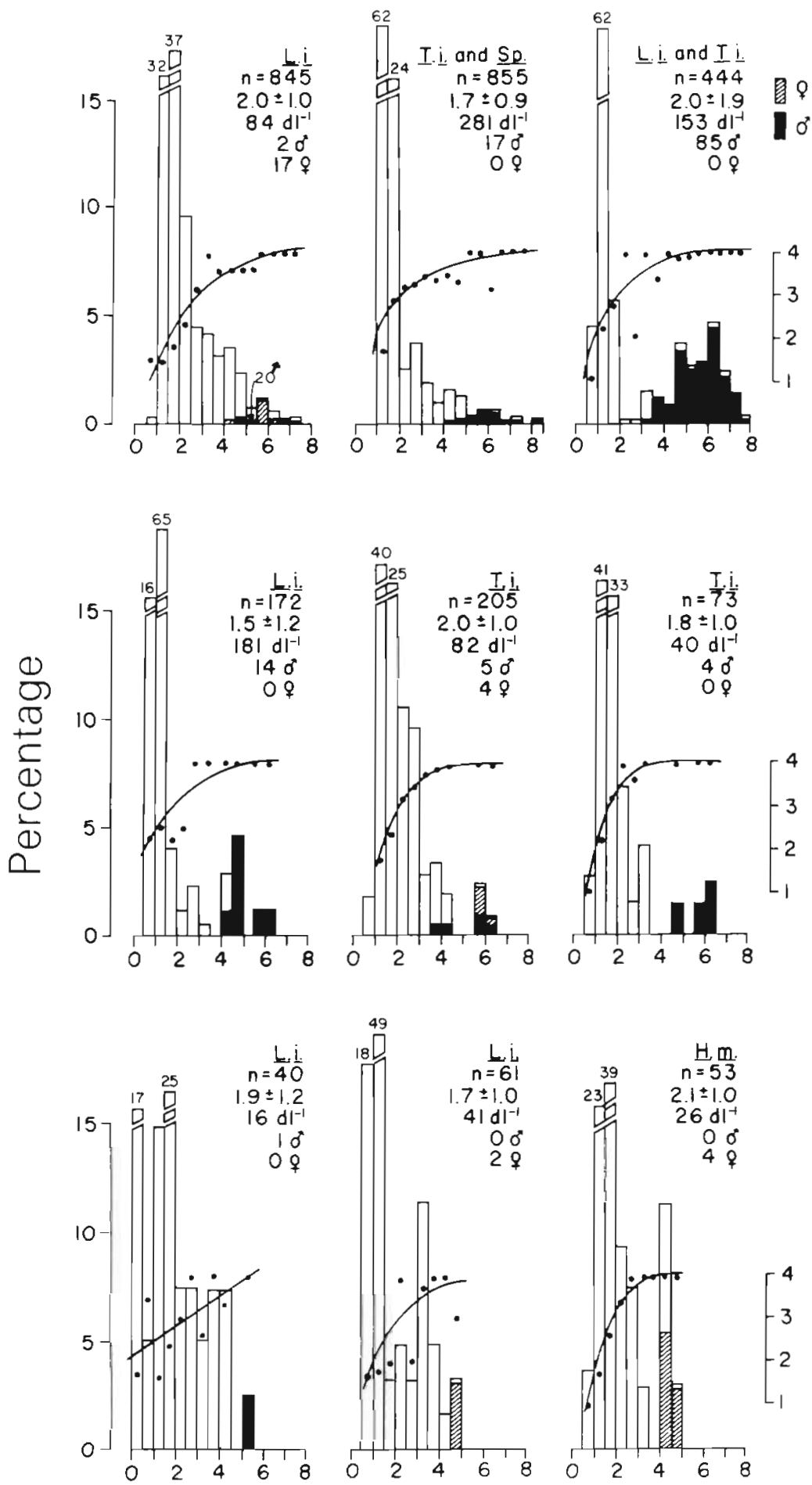

Disc diameter $(\mathrm{mm})$
Fig. 7. Ophiactis savignyi. Size-frequency distribution (histograms), regeneration category as a function of body size (dots), and sexual status (shaded and black areas of histograms) for populations present within 9 different sponges or sponge complexes sampled from Twin Cays mangrove (Fig. 2, Site 3), Belize. The sponge species (H.m.: Haliclona molitba; L.i.: Lissodendoryx isodictyalis; $S p$.: Spongia sp.; T.i.: Tedania ignis), sample size, mean body size ( $\pm 1 \mathrm{SD})$, population density ( $\mathrm{dl}^{-1}$ of sponge), and number of males and females are provided for each sample. The best model equation has been fitted to each set of data points for weighted mean value of regeneration category using the CURFIT program of Spain (1982) 
Table 4. Some characteristics of Ophjactis savignyi in individual sponges in Harrington Sound, Bermuda

\begin{tabular}{|c|c|c|c|c|c|}
\hline Site $^{1}$ & Sponge & $\begin{array}{l}\text { Sponge } \\
\text { volume } \\
\text { (ml) }\end{array}$ & $\begin{array}{c}\text { No. } \\
\text { in sponge }\end{array}$ & $\begin{array}{l}\text { No. with } \\
\text { gonads (all } \\
\text { were males) }\end{array}$ & $\begin{array}{c}\text { Density of fissiparous } \\
\text { brittle stars } \\
\left(\mathrm{dl}^{-1} \text { of sponge) }\right.\end{array}$ \\
\hline 13 & Amphimedon viridis & 50 & 6 & 1 & 12 \\
\hline 13 & Amphimedon viridis & 45 & 10 & 2 & 22 \\
\hline 13 & Amphimedon viridis & 70 & 43 & 2 & 61 \\
\hline 13 & Amphimedon viridis & 150 & 14 & 5 & 9 \\
\hline 14 & Ulosa ruetzleri & 310 & 27 & 5 & 9 \\
\hline 16 & Ulosa ruetzleri & 140 & 16 & 1 & 11 \\
\hline 19 & Tedania ignis & 165 & 3 & 1 & 2 \\
\hline
\end{tabular}

size in all 9 sponges. Only the largest individuals in each sponge were sexual. Of the 9 sponges studied, 5 contained only males, 2 contained only females, and 2 contained males and females. Of the 2748 individuals examined from all 9 sponges, 128 possessed testes and only 27 possessed ovaries. Therefore, about $6 \%$ of the individuals were sexual and of these, about $83 \%$ were males. Therefore, males tended to dominate overall as was found in Falmouth mangrove swamp, Jamaica.

Harrington Sound, Bermuda. Sponges colonized by fissiparous brittle stars occurred throughout Harrington Sound (Table 2). Ophiactis savignyi was by far the most common fissiparous brittle star in sponges, occurring at moderate to high densities (up to $61 \mathrm{dl}^{-1}$ ) in 3 different spocies (Amphimedon viridis, lllosa ruetzleri and Tedania ignis) (Table 4). The characteristics of $O$. savignyi from Bermudan sponges are presented in Fig. 8. The size structure is typical, with many small individuals and only a few large individuals. Value of regeneration category increased with increasing size and only the largest individuals possessed gonads. Interestingly, of the 17 individuals found with gonads (14\% of total), all were males.

\section{DISCUSSION}

\section{Within-habitat comparisons}

Ophiocomella ophiactoides was present in algal turf at both Jamaica and Belize and showed clear evidence of within-habitat variation in density and levels of sexual and asexual reproduction. In algal turf obtained from rather protected coves at Jamaica it was present at moderate to high densities ( $\max .26 \mathrm{dl}^{-1}$ of algae) and reproduced both sexually and asexually. Here, asexual reproduction predominated among many small individuals whereas sexual reproduction predominated among fewer, larger individuals. In algal turf obtained from much more exposed backreef and reef crest areas at Belize, on the other hand, $O$. ophiactoides was present at very low densities (max. $1 \mathrm{dl}^{-1}$ ), showed a higher incidence of fission at all body sizes, and was exclusively asexual.

\section{Between-habitat comparisons}

Ophiactis savignyi was routinely found in both algal turf and sponge habitats at Jamaica, Belize and Bermuda and showed clear evidence of between-habitat differences in population structure and reproductive characteristics. At each location, the mean body size of $O$.

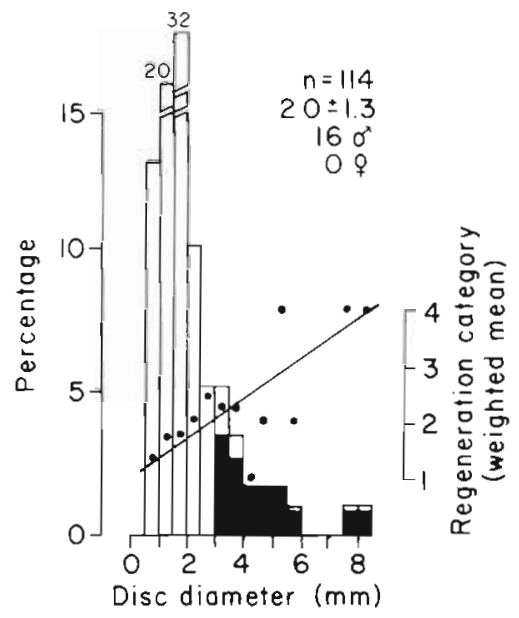

Fig. 8. Ophiactis savignyi. Size-frequency distribution (histogram), regeneration category as a function of body size (dots), and sexual status (black areas of histogram) for pooled samples present in sponges in Harrington Sound, Bermuda (see Fig. 3 and Table 4). Total sample size ( 5 brittle stars from Site 14 [Table 4] were not included because many of their arms were broken during collection), mean body size ( \pm 1 SD), and number of males and females are provided. The best model equation has been fitted to the data points for weighted mean value of regeneration category using the CURFIT program of Spain (1982) 
savignyi in sponges was larger than that of $O$. savignyi in algae $(\mathrm{t}=2.61, \mathrm{p}<0.05 ; \mathrm{t}=2.74, \mathrm{p}<0.01 ; \mathrm{t}=4.25, \mathrm{p}$ $<0.001$ for Jamaica, Belize and Bermuda respectively). At each location, O. savignyi populations in algae occurred at low to moderate densities whereas $O$. savignyi populations in sponges occurred at generally very high densities. Furthermore, at each location $O$. savignyi populations in algae were exclusively or almost exclusively asexual whereas $O$. savignyi populations in sponges contained sexually as well as asexually reproducing individuals. The sexual individuals consisted of a few of the largest brittle stars in the sponge.

\section{Ecological correlates}

Reviews on the distribution of asexual and sexual plants (Levin 1975) and terrestrial animals (Glesener \& Tilman 1978, Bell 1982) suggest that asexual species, in contrast to sexual species, tend to occur in more disturbed, underdeveloped and transient habitats where biotic interactions are less intense. Plant biologists in particular have recognized that asexual organisms tend to be 'weedy', efficient colonizers of transient, disturbed habitats (Stebbins 1950, Wright \& Lowe 1968). Such observations have contributed to the 'tangled bank' hypothesis (Ghiselin 1974, Bell 1982) which views sex as an adaptation to stable, spatially heterogeneous environments in which biotic factors, specifically intraspecific competition, predominate; asexual reproduction on the other hand is viewed as adaptive in habitats kept underdeveloped by disturbance or transience, and where intraspecific competition is less intense. According to this interpretation, heterogonic animals should reproduce asexually when population density is low, thereby saturating a local habitat with genetically identical copies, but switch to sexual reproduction when population density increases, to produce genetically diverse progeny capable of exploiting new and uncrowded habitats. Hughes \& Cancino (1985) and Jackson (1985) suggest that clonal taxa that produce solitary, mobile models may indeed be well suited for exploitation of patchy and physically less stable environments (in contrast to colonial clonal taxa that tend to predominate in physically stable environments), and that asexual reproduction generally persists until growth conditions deteriorate, at which time sexual reproduction ensues. Correlations between high population density, a decline in rate of asexual reproduction, and appearance of sexual individuals have been experimentally demonstrated for the polychaete Pygospio elegans (Wilson 1983) and, in freshwater habitats, for Daphnia spp. and Hydra pseudoligactis (Bell \& Wolfe 1985).

Such ideas and findings might have a bearing on the observed intraspecific differences in population struc- ture and levels of sexual and asexual reproduction in common fissiparous brittle stars. One problem is adequate characterization of the algal and sponge habitats in question. Because of the studies of Hillis-Colinvaux (1980) on the ecology of Halimeda, it is possible to characterize one of the microhabitats frequently occupied by several species of fissiparous brittle stars with some confidence. Thalli of Halimeda grow rapidly and, according to Hillis-Colinvaux (1980), the life cycle 'always seems to involve youth, a maturity measured in months, sometimes longer, senescence and death'. It is noteworthy that during our own studies, we frequently noticed senescent clumps of Halimeda being lifted away from the substratum by wave action. Clumps of Halimeda are likely to be dislodged more frequently in shallow waters where wave action would be more severe. The Halimeda habitat may thus be one of transience and instability, particularly in shallow waters. Equivalent studies on Amphiroa spp., the other major microhabitat for epiphytic fissiparous brittle stars, are not apparently available. However, we frequently observed senescent patches of Amphiroa in the backreef being lifted from the substratum by wave action and currents, and this habitat may also be one of instability and transience.

Little information is available on the ecology and life history of the sponges (Spongia sp., Haliclona molitba, Tedania ignis, Lissodendoryx isodictyalis, Amphimedon viridis and Ulosa ruetzleri) occupied by the fissiparous Ophiactis savignyi. The first 4 species are generally confined to mangrove and lagoonal habitats (Hechtel 1965, Wiedenmayer 1977, Ruetzler pers. comm.). Although accurate information is unavailable, the life span of mangrove sponges is likely around 3 to $10 \mathrm{yr}(\mathrm{K}$. Ruetzler pers. comm., H. Reiswig pers. comm.).

Mangrove sponges may thus represent a more stable habitat than shallow-water algal turf. Ophiactis savignyi in sponges may have the opportunity to create high density populations by fission. Under crowded circumstances, some individuals in the sponge may be stimulated to abandon fission, grow and reproduce sexually. Similarly, it is possible that the apparently greater stability of the algal turf habitat in coves at Jamaica allowed population numbers to increase creating crowded conditions leading to increased allocation of resources to growth and sexuality.

However, trends in size and sexuality in fissiparous brittle stars may be a function of habitat attributes other than stability. For example, nutrient levels (DOM, POM) may be higher in sponges than in algal turf as well as higher in protected than in exposed turf. This might result in higher growth rates, larger body size and the onset of sexual reproduction. Altematively, sponges may represent superior 'refuge-substrata' (Hendler \& Littman 1986) than algal turf so there may be greater 
predation on the larger sexual fissiparous brittle stars in algae compared to sponges. Further research involving experimental manipulation of habitat and population densities are necessary to test these various hypotheses.

\section{Evidence of clonal aggregations}

Two lines of indirect evidence support the inference that fissiparous brittle stars can form clonal aggregations in algae. Firstly, populations of Ophiocomella ophiactoides and Ophiactis savignyi in algae were often contagiously distributed, especially at higher densities. Secondly, for $O$. ophiactoides, a species in which the overall sex ratio is 1 (this study and Mladenov \& Emson 1984), we found extremely biased sex ratios and the frequent occurrence of all-male or all-female clusters in samples taken from discrete clumps of algae. Both observations are consistent with the notion that algal patches are occupied by one or a few small, clonal clusters of brittle stars. It is possible that colonization of algae often occurs through isolated founding events, either by settlement of a single larva or movement of a single adult into a patch from an adjacent area. A cluster of clone-mates then forms that expands outwards from the point of colonization. Expanding clones may eventually overlap with other clones, thus accounting for patches with both males and females.

Similar arguments for clonality apply to fissiparous brittle star populations in sponges. We documented extremely high donsities of Ophiactis savignyi in sponges consistent with the idea of a rapidly expanding clone saturating a previously unclerdeveloped habitat. More revealing, however, was the finding that sponges are frequently occupied by all-male aggregations of brittle stars and, sometimes, by all-female aggregations On this criterion, we suspect that sponges may often be occupied by a limited number of clones. Electrophoretic studies (Mladenov \& Emson unpubl.) should provide further information on the number of clones present in algal and sponge habitats provided that an adequate number of polymorphic enzyme loci can be detected in gels.

\section{Dispersal and the efficiency of sexual reproduction}

We have shown that sexual reproduction, and thus the production of a pelagic larval dispersal stage (Mladenov \& Emson 1984), can be rare or absent in populations of fissiparous brittle stars, especially those colonizing algal habitats at low density. Therefore, the potential for dispersal and colonization of new habitats may be limited. This apparent problem may be diminished by alternate dispersal mechanisms, including rafting
Hillis-Colinvaux (1980) suggests that fragments of Halimeda produced by waves can be transported by currents and, under favourable conditions, become reestablished and develop into complete thalli. We commonly observed clumps of Amphiroa in the water column in Discovery Bay, Jamaica, especially following days when the sea had been rough. Floating clumps of Halimeda and Amphiroa may provide a means of dispersal for individuals of exclusively asexual epiphytic brittle star populations. Algal rafting also appears to be a dispersal mechanism for the small brooding brittle star, Amphipholis squamata (Highsmith 1985).

It is conceivable that fissiparous brittle stars living in sponges crawl out of the sponge and disperse short distances to other nearby sponges. It is also possible that sponge-dwelling fissiparous brittle stars could be dispersed by rafting within sponges that have become dislodged, particularly during storms. Production of a larval stage might play a role in long-distance dispersal, but a complicating factor is the observed male domination of Ophiactis savignyi populations in sponges at all of the locations that we studied. In the whole of Harrington Sound, Bermuda, not one female was discovered, while females constituted only 11 and $17 \%$ of the sexual individuals examined from sponges at Jamaica and Belize. Furthermore, when males and females were both present at any one location, they generally occurred in different sponges. Under these circumstances the efficiency of sexual reproduction must be very low and one must wonder whether it often serves any useful function.

It is difficult to explain the predominance of male Ophiactis savignyi in sponges. A number of factors may be involved. Male clones may be better adapted for life in the sponge interior and may outcompete female clones. Alternatively, random founding events may be invoked. In any case, the occurrence of an apparently all-male population of $O$. savignyi in Harrington Sound is intriguing and perhaps comparable to the finding of all-male populations of the fissiparous sea anemone Haliplanella luciae in Maine (Shick 1976, Shick \& Lamb 1977). Perhaps the entire O. savignyi population in Harrington Sound comprises one or more male clones. Again, an electrophoretic study may be helpful.

Acknowledgements. We thank the Director and staff of the Discovery Bay Marine Laboratory of the University of the West Indies, Jamaica and of the Bermuda Biological Station for Research, Inc. for providing facilities and assistance. We are grateful to K. Ruetzler and the National Museum of Natural History (Smithsonian Institution) for providing equipment during our stay at Southwater Cay, Belize. Dr Ruetzler also kindly identified sponges. We thank Therese Bowman for her hospitality and logistical support during our stay in Dangriga, Belize. Sally Carson assisted with the field work and Kevin Brady assisted with data analysis. G. Hendler and D. Pawson provided helpful information at the outset of this study and D. 
Pawson confirmed the identity of some of our Bermudan brittle stars. We thank G. Bell, G. Hendler and J. Pearse for their suggestions concerning an earlier version of this manuscript. This research was supported by the National Geographic Society (Grant \#2839-84), the National Sciences and Engineering Research Council of Canada (Grant \#A7604 to P. V Mladenov) and the Donner Canadian Foundation.

\section{LITERATURE CITED}

Bell, G. (1982). The masterpiece of nature. The evolution and genetics of sexuality. Croom Helm Ltd., London

Bell, G., Wolfe, L. M. (1985). Sexual and asexual reproduction in a natural population of Hydra pseudoligactis. Can. J. Zool. 63: 851-856

Chia, F. S. (1976). Sea anemone reproduction: patterns and adaptive radiations. In: Mackie, G. O. (ed.) Coelenterate ecology and behavior. Plenum Publishing, New York, p. $261-270$

Clark, H. L. (1933). A handbook of the littoral echinoderms of Porto Rico and the other West Indian Islands. New York Academy of Sciences Scientific Survey of Porto Rico and the Virgin Islands 16: $1-147$, and 7 plates

Clark, H. L. (1942). The echinoderm fauna of Bermuda. Bull. Mus. comp. Zool. Harv. 89: 367-391, and 1 plate

Crump, R. G., Barker, M. F. (1985). Sexual and asexual reproduction in geographically separated populations of the fissiparous asteroid Coscinasterias calamaria (Gray). J. exp. mar. Biol. Ecol. 88: 109-127

Elliott, J. M. (1977). Some methods for the statistical analysis of samples of benthic invertebrates. Freshwater Biological Association Scientific Publication No. 25. Titus Wilson and Son Ltd., Kendal, England

Emson, R. H., Wilkie, I. C. (1980). Fission and autotomy in echinoderms. Oceanogr. mar. Biol. A. Rev. 18: 155-250

Emson, R. H., Wilkie, I. C. (1984). An apparent instance of recruitment following sexual reproduction in the fissiparous brittlestar Ophiactis savignyi Muller \& Troschel. J. exp. mar. Biol. Ecol. 77: 23-28

Emson, R. H., Mladenov, P. V., Wilkie, I. C. (1985). Patterns of reproduction in small Jamaican brittle stars: fission and brooding predominate. In: Reaka, M. L. (ed.) The ecology of coral reefs. NOAA Symposium Series for Undersea Research 3. NOAA Undersea Research Program, Rockville, Maryland, p. 87-100

Ghiselin, M. T (1974). The economy of nature and the evolution of sex. Univ. of California Press, Berkeley, Ca.

Glesener, R. R., Tilman, D. (1978). Sexuality and components of environmental uncertainty: clues from geographical parthenogenesis in terrestrial animals. Am. Nat. 112: 659-673

Hechtel, G. J. (1965). A systematic study of the Demospongiae of Port Royal, Jamaica. Yale University, Peabody Museum of Natural History, Bulletin 20. New Haven, Connecticut, p. $1-103$

Hendler, G., Littman, B. S. (1986). The ploys of sex: relationships among the mode of reproduction, body size and habitats of coral-reef brittlestars. Coral Reefs $5: 31-42$

Highsmith, R. C. (1985). Floatıng and algal rafting as potential dispersal mechanisms in brooding invertebrates. Mar. Ecol. Prog. Ser. 25: 169-179

Hillis-Colinvaux, L. (1980). Ecology and taxonomy of Halimeda: primary producer of coral reefs. Adv. mar Biol 17. $1-327$
Hoffmann, R. J. (1986). Variation in contributions of asexual reproduction to the genetic structure of populations of the sea anemone Metridium senile. Evolution 40: 357-365

Hotchkiss, F. H. C. (1982). Ophiuroidea (Echinodermata) from Carrie Bow Cay, Belize. In: Rutzler, K., Macintyre, I. G. (eds.) The Atlantic barrier reef ecosystem at Carrie Bow Cay, Belize, I: Structure and communities. Smithsonian Contributions to the Marine Sciences 12. Smithsonian Institution Press, Washington, p. 387-412

Hughes, R. N., Cancino, J. M. (1985). An ecological overview of cloning in metazoa. In: Jackson, J. B. C., Buss, L. W., Cook R. E. (eds.) Population biology and evolution of clonal organisms. Yale Univ. Press, New Haven, p. 153-186

Jackson, J. B. C. (1985). Distribution and ecology of clonal and aclonal benthic invertebrates. In: Jackson, J. B. C., Buss, L. W., Cook, R. E. (eds.) Population biology and evolution of clonal organisms. Yale Univ. Press, New Haven, p. 297-355

James, D. B., Pearse, J. S. (1969). Echinoderms from the Gulf of Suez and the northern Red Sea. J. mar. biol. Ass. India 11: 78-125

Koehler, R. (1913). Ophiures. Zool. Jb. 11 (Suppl.): 351-380 and plates 20,21

Levin, D. A. (1975). Pest pressure and recombination systems in plants. Am. Nat. 109: 437-451

Mladenov, P. V., Emson, R. H., Colpitts, L. V., Wilkie, I. C. (1983). Asexual reproduction in the West Indian brittle star Ophiocomella ophiactoides (H. L. Clark) (Echinodermata: Ophiuroidea). J. exp. mar Biol. Ecol. 72: 1-23

Mladenov, P. V., Emson, R. H. (1984). Divide and broadcast: sexual reproduction in the West Indian brittle star Ophiocomella ophiactoides and its relationship to fissiparity. Mar. Biol. 81: 273-282

Mladenov, P. V., Powell, I. (1986). A simple underwater magnifying device for the diving biologist. Bull. mar. Sci. 38: 558-561

Morris, B., Barnes, J., Brown, F., Markham, J. (1977). The Bermuda marine environment. A report of the Bermuda inshore waters investigations 1976-1977. Bermuda Biological Station Special Bulletin No. 15, St. Georges West, Bermuda

Parslow, E. R., Clark, A. M. (1963). Ophiuroidea of the Lesser Antilles. Stud. Fauna Curacao 15: 24-50

Shick, J. M. (1976). Ecological physiology and genetics of the colonizing actinian Haliplanella luciae. In: Mackie, G. O. (ed.) Coelenterate ecology and behavior. Plenum Press, New York, p. 137-1.46

Shick, J. M., Lamb, A. N. (1977). Asexual reproduction and genetic population structure in the colonizing sea anemone Haliplanella luciae. Biol. Bull. mar. biol. Lab., Woods Hole 153: $604-617$

Spain, J. D. (1982). Basic microcomputer models in biology Addison-Wesley, London

Stebbins, G. L. (1950). Variation and evolution in plants. Columbia University Press, New York

Thomas, L. P. (1962). The shallow water amphiurid brittle stars (Echinodermata, Ophiuroidea) of Florida. Bull. mar. Scl. Gulf Carbb. 12: 623-694

Wiedenmayer, F. (1977). Shallow-water sponges of the western Bahamas. Experientia 28 (Suppl.): $1-287$ and 43 plates

Wilson, W. H. (1983). The role of density dependence in a marine infaunal communiry Ecology 64: 295-306

Wright, J. W., Lowe, C. J. (1968). Weeds, polyploids, parthenogenesis, and the geographical and ecological distribution of all-female species of (nemidophorous. Copeia 1968: $128-138$ 